\title{
PARP1 inhibitor eliminated imatinib-refractory chronic myeloid leukemia cells in bone marrow microenvironment conditions
}

\author{
Paulina Podszywalow-Bartnicka ${ }^{a, b}$, Silvia Maifrede ${ }^{a}$, Bac Viet Le ${ }^{a, b}$, Margaret Nieborowska- \\ Skorska ${ }^{\mathrm{a}}$, Katarzyna Piwocka ${ }^{\mathrm{b}}$, and Tomasz Skorski ${ }^{\mathrm{a}}$
}

aTemple University Lewis Katz School of Medicine, Department of Microbiology and Immunology and Fels Institute for Cancer Research \& Molecular Biology, Philadelphia, PA, USA bNencki Institute of Experimental Biology, Laboratory of Cytometry, Warsaw, 02-083, Poland

Treatment with tyrosine kinase inhibitors (TKIs) results in remission and prolongation of survival but fails to eliminate the leukemia stem cells (LSCs) responsible for disease development and propagation in most chronic myeloid leukemia (CML) patients [1]. In concordance discontinuation of TKi therapy usually leads to rapid leukemia relapse. Most patients require continued treatment to prevent relapse, with associated risk of relapse, toxicity, teratogenic effects, financial burden, and noncompliance.

Bone marrow niche microenvironment (BMM) is known to play an important role in regulating LSC maintenance and in protecting LSCs from anti-leukemia treatment [2]. It has been reported that CML-CP cells survive TKI treatment in bone marrow niche, which may contribute to persistent presence of residual CML-CP cells in TKI-treated patients. Therefore development of strategies eradicating LSCs from BMM is a critical area of investigation in CML to increase the proportion of CML patients achieving a cure.

We reported before that CML-CP LSCs and LPCs accumulate high numbers of potentially lethal DNA double-strand breaks (DSBs) [3,4]. Moreover, BCR-ABL1 kinase causes downregulation of BRCA1 and DNA-PKcs proteins, which play key roles in two major DSB repair pathways: homologous recombination (HR) and classical non-homologous endjoining (cNHEJ), making TKI-naive CML cells susceptible to synthetic lethality triggered by PARP1 inhibitors [5-9]. On the other hand, TKI-mediated inhibition of BCR-ABL1 kinase caused downregulation of RAD51 (key role in HR) and LIG4 (key role in cNHEJ) were associated with PARP1 inhibitor-mediated synthetic lethality [8]. Altogether, TKInaive and TKI-treated CML cells display specific defects in DSB repair and are sensitive to synthetic lethality induced by PARP1 inhibitors in standard in vitro liquid culture conditions in normoxia [9].

To test if PARP1 inhibitor is effective against CML cells in the conditions mimicking BMM HS-5 human bone marrow stromal cell line cells (secrete significant levels of G-CSF, GM-

Correspondence: Tomasz Skorski, Temple University Lewis Katz School of Medicine, Department of Microbiology \& Immunology, 3400 N. Broad Street, MRB 548, Philadelphia, PA, 19140, USA. Phone: 215-707-9157, Fax: 215-707-9160, tskorski@ temple.edu. 
CSF, M-CSF, SCF, MIP1a, IL-6, IL-8, and IL-11 to support the growth of hematopoietic stem cells [10]) were co-cultured for $24 \mathrm{hrs}$ under hypoxia $\left(1 \% \mathrm{O}_{2}\right)$ with imatinib-sensitive primary Lin-CD34+ ${ }^{+}$CML-CP cells collected at diagnosis (1:1 cell ratio). Then BCR-ABL1 kinase inhibitor imatinib and/or PARP1 inhibitor talazoparib were added for 3 days followed by evaluation of DSBs by $\gamma$-H2AX immunofluorescence and neutral comet assay, proliferation by clonogenic activity, and of leukemia engraftment in humanized immunodeficient NRGS mice (Fig. 1).

As expected [11,12] Lin-CD34+ CML-CP cells were protected from imatinib in BMM-like conditions (Fig. 2A-C). Talazoparib modestly increased the number of DSBs and decreased clonogenic activity of these cells in concordance with our report that CML cells are BRCA1 and DNA-PKcs -deficient [9] and other report [13] that hypoxia promotes HR-deficiency and sensitivity to PARP1 inhibitor-mediated synthetic lethality.

Remarkably, talazoparib increased DSBs and inhibited clonogenic potential of imatinibrefractory CML-CP cells. Moreover, talazoparib reduced the number of imatinib-refractory CML-CP cells (Fig. 2D), including Lin-CD34+ cells (Fig. 2E) capable to engraft in immunodeficient mice. However, the effect of PARP1 inhibitor against imatinib-treated CML-CP cells in BMM-like conditions appears less profound than that previously reported in the absence of stromal cells in normoxia [9].

In conclusion, we postulate that while BMM protects CML-CP cells from TKIs, it provides limited protection against PARP1 inhibitors. Therefore PARP1 inhibitors could be applied together with TKIs to target TKI-refractory CML-CP cells in BMM, which should reduce the risk of disease relapse. The anti-CML effect of imatinib + olaparib in BMM conditions, however, is not as robust as that observed in normoxia implicating niche-specific protective impact, which requires further investigation.

\section{Acknowledgements:}

This work was supported by NHI/NCI 1R01 CA186238 to T.S. P.P-B. was supported by the grant from Polish National Science Centre 2014/15/D/NZ3/05187 and by Kosciuszko Foundation Scholarship for 2016/2017. B.V.L has been supported by the European Union's Horizon 2020 Research and Innovation Programme under the Marie Sklodowska-Curie grant agreement no 665735 and by the funding from Polish Ministry of Science and Higher Education funds for the implementation of international projects, 2016-2020.

\section{References:}

1. Bhatia R Novel approaches to therapy in CML. Hematology Am Soc Hematol Educ Program 2017;2017:115-120. [PubMed: 29222245]

2. Agarwal P, Bhatia R. Influence of Bone Marrow Microenvironment on Leukemic Stem Cells: Breaking Up an Intimate Relationship. Adv Cancer Res 2015;127:227-52. [PubMed: 26093902]

3. Bolton-Gillespie E, Schemionek M, Klein HU, Flis S, Hoser G, Lange T, Nieborowska-Skorska M, Maier J, Kerstiens L, Koptyra M and others. Genomic instability may originate from imatinibrefractory chronic myeloid leukemia stem cells. Blood 2013;121:4175-83. [PubMed: 23543457]

4. Nieborowska-Skorska M, Kopinski PK, Ray R, Hoser G, Ngaba D, Flis S, Cramer K, Reddy MM, Koptyra M, Penserga T and others. Rac2-MRC-cIII-generated ROS cause genomic instability in chronic myeloid leukemia stem cells and primitive progenitors. Blood 2012;119:4253-63. [PubMed: 22411871] 
5. Deutsch E, Dugray A, AbdulKarim B, Marangoni E, Maggiorella L, Vaganay S, M'Kacher R, Rasy $\mathrm{SD}$, Eschwege F, Vainchenker $\mathrm{W}$ and others. BCR-ABL down-regulates the DNA repair protein DNA-PKcs. Blood 2001;97:2084-90. [PubMed: 11264175]

6. Deutsch E, Jarrousse S, Buet D, Dugray A, Bonnet ML, Vozenin-Brotons MC, Guilhot F, Turhan AG, Feunteun J, Bourhis J. Down-regulation of BRCA1 in BCR-ABL-expressing hematopoietic cells. Blood 2003;101:4583-8. [PubMed: 12576338]

7. Podszywalow-Bartnicka P, Wolczyk M, Kusio-Kobialka M, Wolanin K, Skowronek K, Nieborowska-Skorska M, Dasgupta Y, Skorski T, Piwocka K. Downregulation of BRCA1 protein in BCR-ABL1 leukemia cells depends on stress-triggered TIAR-mediated suppression of translation. Cell Cycle 2014;13:3727-41. [PubMed: 25483082]

8. Slupianek A, Poplawski T, Jozwiakowski SK, Cramer K, Pytel D, Stoczynska E, Nowicki MO, Blasiak J, Skorski T. BCR/ABL stimulates WRN to promote survival and genomic instability. Cancer Res 2011;71:842-51. [PubMed: 21123451]

9. Nieborowska-Skorska M, Sullivan K, Dasgupta Y, Podszywalow-Bartnicka P, Hoser G, Maifrede S, Martinez E, Di Marcantonio D, Bolton-Gillespie E, Cramer-Morales K and others. Gene expression and mutation-guided synthetic lethality eradicates proliferating and quiescent leukemia cells. J Clin Invest 2017;127:2392-2406. [PubMed: 28481221]

10. Roecklein BA, Torok-Storb B. Functionally distinct human marrow stromal cell lines immortalized by transduction with the human papilloma virus E6/E7 genes. Blood 1995;85:997-1005. [PubMed: 7849321]

11. Ng KP, Manjeri A, Lee KL, Huang W, Tan SY, Chuah CT, Poellinger L, Ong ST. Physiologic hypoxia promotes maintenance of CML stem cells despite effective BCR-ABL1 inhibition. Blood 2014;123:3316-26. [PubMed: 24705490]

12. Vianello F, Villanova F, Tisato V, Lymperi S, Ho KK, Gomes AR, Marin D, Bonnet D, Apperley J, Lam EW and others. Bone marrow mesenchymal stromal cells non-selectively protect chronic myeloid leukemia cells from imatinib-induced apoptosis via the CXCR4/CXCL12 axis. Haematologica 2010;95:1081-9. [PubMed: 20179085]

13. Chan N, Pires IM, Bencokova Z, Coackley C, Luoto KR, Bhogal N, Lakshman M, Gottipati P, Oliver FJ, Helleday T and others. Contextual synthetic lethality of cancer cell kill based on the tumor microenvironment. Cancer Res 2010;70:8045-54. [PubMed: 20924112]

14. Koptyra M, Falinski R, Nowicki MO, Stoklosa T, Majsterek I, Nieborowska-Skorska M, Blasiak J, Skorski T. BCR/ABL kinase induces self-mutagenesis via reactive oxygen species to encode imatinib resistance. Blood 2006;108:319-27. [PubMed: 16527898] 


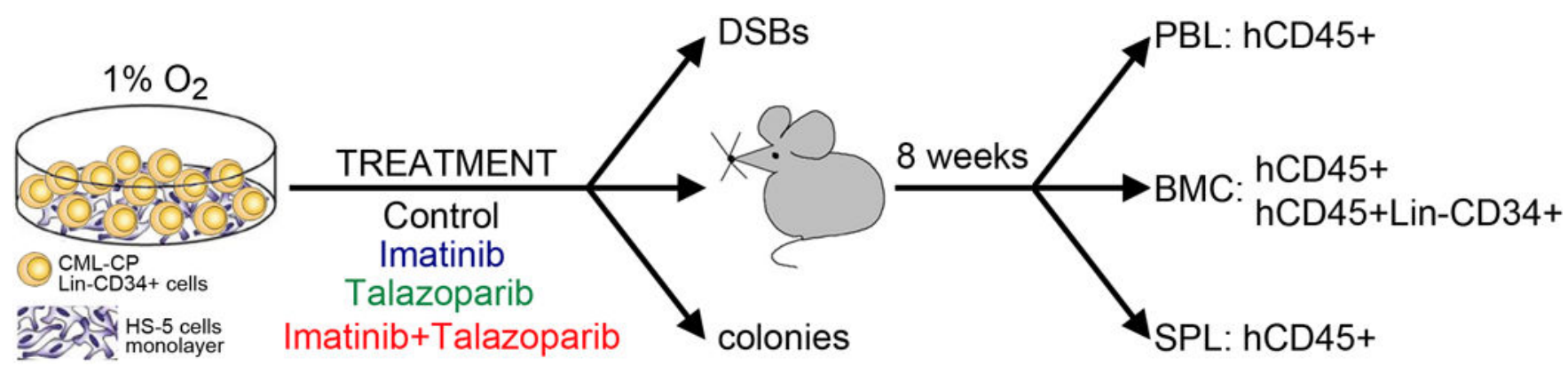

Figure 1. Experimental protocol.

CML-CP Lin-CD34+ cells were plated on HS-5 cells monolayer (1:1 ratio) and incubated in hypoxia $\left(1 \% \mathrm{O}_{2}\right)$ with diluents (Control), imatinib $(\mathrm{I}, 1 \mu \mathrm{M})$, talazoparib $(\mathrm{T}, 100 \mathrm{nM})$, and imatinib + talazoparib. Leukemia cells were then collected and tested. DSBs were detected in CML-CP cells by neutral comet assay and $\gamma$-H2AX immunofluorescence as described before $[4,14]$. CML-CP cells were plated in methylcellulose and colonies were counted after 7 days as described before [4]. In addition, $2 \times 10^{6} \mathrm{CML}-\mathrm{CP}$ cells were injected i.v. in to the total body irradiated (600 cGy) mice and leukemia engraftment was assessed 8 weeks later by immunofluorescence [human CD45 (hCD45+), hCD45+Lin-CD34+] in peripheral blood leukocytes (PBL), splenocytes (SPL) and bone marrow cells (BMC) as described before [9]. 

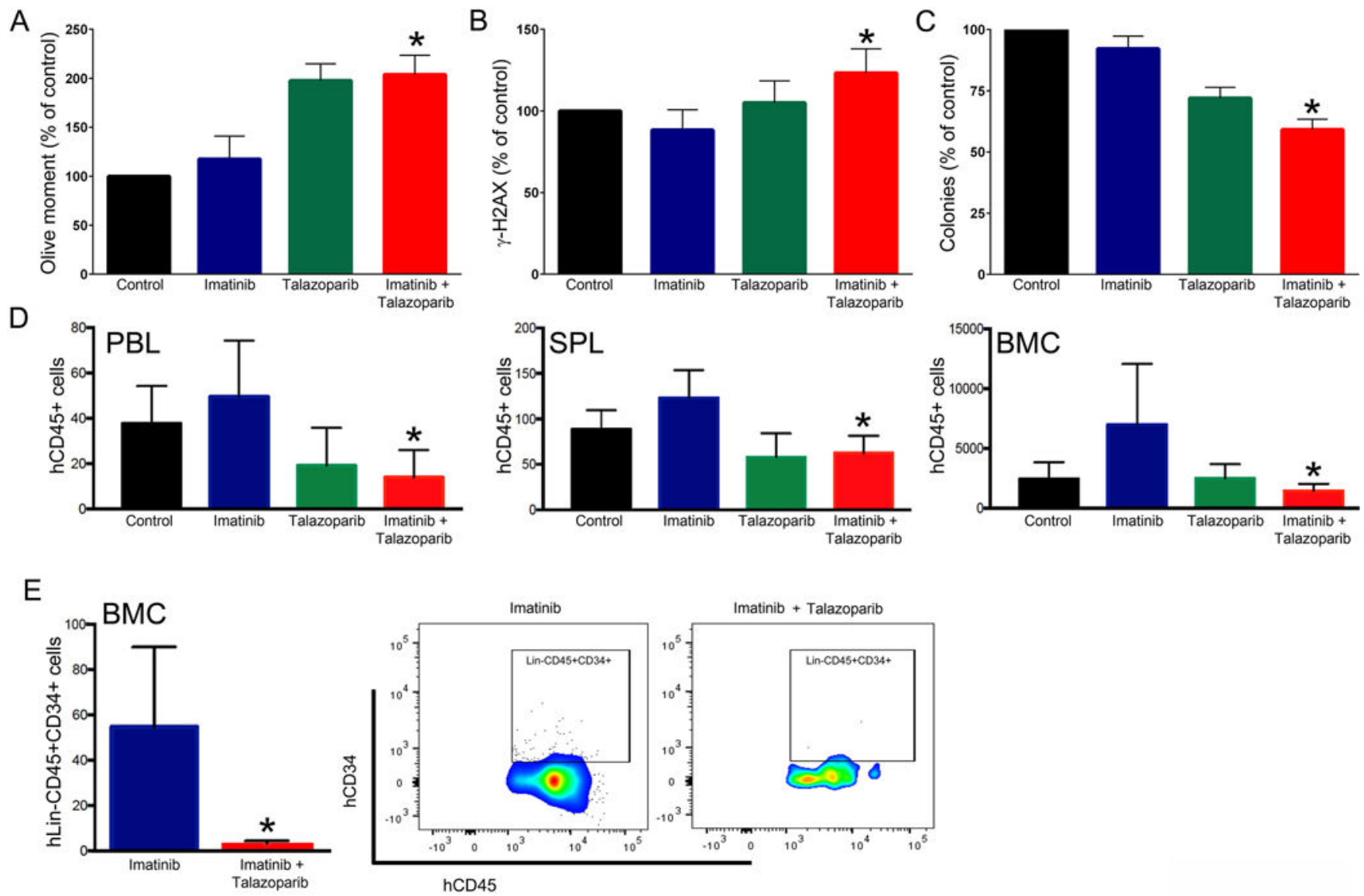

Figure 2. Talazoparib induced DSBs and eliminated imatinib-refractory CML-CP primary cells in the presence of hematopoietic stromal cells and hypoxia.

(A) DNA damage examined by comet assay after $24 \mathrm{~h}$ of treatment as described before [14]. Olive tail moment was determined in $3 \mathrm{CML}-\mathrm{CP}$ samples (each sample in triplicate) using ImageJ/Open Comet software. Results represent mean value of olive tail moment presented as $\%$ of control $\pm \mathrm{SD}$. (B) Level of $\gamma$-H2AX in live Ki67+ cells was analyzed after $24 \mathrm{~h}$ of treatment and is presented as mean fluorescence intensity \pm SD from 3 CML-CP samples (each sample in triplicate) as described before [4]. (C) Clonogenic potential determined by 7 day colony formation assay as described before [9]. Number of colonies calculated for 6 different patient samples (each in triplicate) is presented as mean \% of control \pm SD. (D) CML-CP cells were detected by immunofluorescent staining with anti-human CD45, antilineage markers (Lin), and anti-CD34 antibodies. Mean number \pm SD of hCD45+ cells per $10^{6} \mathrm{PBL}, \mathrm{SPL}$ and BMC from 5 mice/group. (E) Mean number \pm SD of hCD45+Lin-CD34+ cells in BMC from 5 mice/group; representative dot plots are shown. Student's two tailed ttest was used to compare results from Imatinib and Talazoparib+Imatinib treated cells; * $\mathrm{p}<0.05$. 